\title{
China's green insurance system and functions
}

\author{
Sergey A. Belozyorov, and Xiaohe Xie \\ St.-Petersburg State University, 199034, Universitetskaya Emb., 7-9, Saint Petersburg, Russian
}

\begin{abstract}
The article aims at the relationship between China's green insurance, social and economic development, and environmental protection. It analyzes China's green insurance development measures and operating mechanism. According to the China Statistical Yearbook, based on data from 2011-2019, research variables are selected for empirical analysis and qualitative analysis. It is concluded that the green insurance industry is conducive to sustainable and sustainable development, reduces industrial transformation risks, improves environmental protection capabilities, and improves residents' living standards. China's experience in developing the green insurance industry provides a useful reference for the sustainable development and development of green finance in developing countries and regions.
\end{abstract}

\section{Introduction}

Green insurance provides insurance products that support environmental improvement, respond to climate change, and promote resource conservation and efficient use. It also provides environmental risk management services. China is at the forefront of green finance initiatives globally with most beneficiaries being developing countries with a stable political environment with significantly high levels of creditrisk.[1]

From the perspective of the industrial chain, China's insurance industry has gradually enriched green insurance products and services, providing risk protection and risk management services for green energy, green transportation, green buildings, green technology, climate governance, and forest carbon sinks. With the continuous growth of insurance investment in China's green industry projects, an insurance fund operation model with Chinese characteristics has been formed. According to statistics, from 2018 to the end of 2020, the green investment stock of China's insurance funds has increased from 3954 billion rubles to 5,615 billion rubles, a growth rate of $19.17 \%$.[2]

"China's Fourteenth Five-Year Plan for National Economic and Social Development and the Outline of 2035 Vision Goals" and carbon emission targets force its industries to face the need for green transformation and are in the process of transformation and development. The risk of the process requires the insurance industry to undertake corresponding social responsibilities, which meets the market demand for social and economic development. [3]From the perspective of the sustainable development of the insurance industry, the dramatic increase in insurance risk events caused by global climate change, rising claims costs, and challenges in underwriting and pricing have led the insurance industry to actively seek solutions that take into account both availability. 
Green insurance is an important part of green finance. China has improved its legal system to guide the development of green insurance and build a comprehensive green insurance system.[4] The establishment of an environmental pollution liability insurance system should promote cooperation between insurance companies and other financial institutions to jointly promote the development of environmental pollution liability insurance.[5]

Establishing a unique green financial system and actively promoting and developing green insurance will help improve the corporate risk management system and help the insurance industry to carry out supply-side structural reforms. Build a sound environmental protection system The credit system and the green financial system can accelerate the green transformation of the economy. [6] The functions of timely compensation, reduction of management costs, risk control and other functions of green insurance meet the needs of China's environmental protection. The establishment of a green insurance system requires legitimacy Corresponding policies and measures shall be adopted in terms of system models, insurance coverage and types of insurance, and the design of supporting mechanisms. [7]Studying the impact of financing constraints on green innovation and exploring the financing constraints of enterprises on green innovation are important topics for the development of Chinese enterprises.

The green insurance mechanism provides property and personal insurance products and services for the needs of energy-saving and environmentally-friendly enterprises, and provides comprehensive risk protection for their production and operation. It can disperse risks in the process of energy conservation and environmental protection technology and equipment research and development, promote the development of energy conservation and environmental protection technology, improve energy conservation and emission reduction, accelerate the construction of a green production system, and form a new economic growth point. By improving the green insurance supply system, the insurance industry will give full play to its functions of economic compensation, financing and risk management, increase the "green supply" of the whole society, and promote supply-side structural reforms.

Based on the green insurance development model of developed countries, China has formulated relevant administrative regulations and local regulations on the basis of environmental protection law and insurance law, and established a legal guarantee for the development of green insurance in the form of legislation. In the form of legislation, the areas of insurance, the methods of insurance, and incentive and restraint mechanisms are clarified. At the same time, a strict environmental damage compensation system is implemented to clarify the responsibilities that enterprises should bear for harming the environment, and to increase the cost of damage to the ecological environment. An effective accountability mechanism forces companies to purchase environmental pollution liability insurance to diversify and resolve environmental risks. In addition, the Chinese government supports the establishment of specialized insurance companies, takes the lead in formulating insurance policies, and supervises implementation, etc., and actively exerts the government's guiding and supporting role.

With policy support, we will accelerate the pace of insurance product R\&D and innovation, green insurance products and services, increase the effective supply of green insurance, and guide insurance funds to support the development of green industries. Promote the insurance industry's in-depth participation in environmental risk management, in-depth participation in the entire environmental risk management process of insured companies, and comprehensively improve the company's environmental risk management level.

In order to develop the green insurance industry, an innovation-driven development strategy has been implemented to accelerate innovation in the insurance industry's institutional mechanisms, products and services, and business models. The development of 
the digital economy makes full use of insurance technologies such as the mobile Internet, big data, and cloud computing to improve the level of operation and management, and improve the efficiency of operation and management of green insurance companies. Insurtech has changed the business model and process of insurance companies, the insurance industry has undergone a deep reorganization, and has reshaped the value chain of the insurance industry. The insurance industry is realizing process digitization, experience intelligence, content customization, and online channels.

The green insurance strategy has also differentiated business models, such as professional operations by customer groups, insurance + technology, and insurance + ecology. The development of insurance business attaches importance to improving the quality and efficiency of development, strengthening the management of asset-liability matching, and taking the road of sustainable development.

China has established a credit system for the insurance industry, and is connected to platforms such as bank credit reporting systems to realize information sharing, form an effective trustworthy incentive mechanism and untrustworthy punishment mechanism, and optimize the credit environment for the green and sustainable development of the insurance industry.

\section{Data, descriptive statistics and empirical strategy}

Developed countries have a relatively high level of economic development and relatively low environmental pressure, so the development of green insurance is mainly to deal with climate change. Unlike developed countries, green insurance in developing countries must take into account environmental pollution control and climate change. The main direction of China's development of green insurance is to support environmental improvement, address climate change, and promote resource conservation and efficient use. China introduce both green insurance and insurance subsidy.[8]

For the purpose of the research, we put forward a hypothesis: the insurance industry promotes China's economic growth and industrial upgrading, improves the quality of life of residents, and improves China's environment at the same time. And use the data from the China Statistical Yearbook and the Environmental Bulletin to do a trend analysis, and then obtain a qualitative analysis of the long-term impact of the development of green insurance on China's social and economic development.

The empirical analysis in this paper is based on the panel data variable indicators from 2011 to 2019 from the "China Statistical Yearbook" and "Chinese Ministry of Environmental Protection Bulletin." In order to study the correlation between insurance, economic growth and environmental protection capabilities, five representative variables were selected: X1- green insurance compensation funds, X2- industrial pollution control funds, X3- environmental protection investment funds, X4-GDP, X5-per capita GDP as research variable. Variable description and data are shown in Table 1. We use insurance compensation funds to measure the contribution of the insurance industry to economic development and environmental protection. GDP is used as a regional economic development indicator, per capita GDP is used to measure the living standards of residents, and industrial pollution control funds and environmental protection investment funds are used as environmental protection construction capabilities. 
Table 1. Research variables and data.

\begin{tabular}{|c|c|c|c|c|c|}
\hline year & X1(RUB bln) & X2(RUB bln) & X3(RUB bln) & X4(RUB bln) & X(Yuan) \\
\hline 2011 & 3929 & 444.36 & 7114.03 & 483392.8 & 36277 \\
\hline 2012 & 4716 & 500.45 & 8253.46 & 537329 & 39771 \\
\hline 2013 & 6213 & 849.66 & 9037.2 & 588141.2 & 43497 \\
\hline 2014 & 7216 & 997.7 & 9575.5 & 644380.2 & 46912 \\
\hline 2015 & 8674 & 777.3 & 8806.3 & 685571.2 & 49922 \\
\hline 2016 & 10515.68 & 819 & 9216.8 & 742694.1 & 53783 \\
\hline 2017 & 11181 & 681.5 & 9538.95 & 830945.7 & 59592 \\
\hline 2018 & 12297 & 621.3 & 9539 & 915243.5 & 65534 \\
\hline 2019 & 12893.97 & 615.2 & 9800 & 983751.2 & 70328 \\
\hline
\end{tabular}

Note: National Bureau of Statistics of China, Ministry of Environmental Protection

Because the variable numbers are large and the units are not uniform, we first perform logarithmic processing on the variables and then perform subsequent analysis. From the results of the analysis in Table 2, it can be seen that the overall quality of the data is good, and the skewness and kurtosis of the variables are within a reasonable range, and the next step can be analyzed.

Table 2. Descriptive analysis results of variables.

\begin{tabular}{|c|c|c|c|c|c|c|c|c|c|}
\hline Variables & Obs & Mean & Std. Dev. & Min & Max & p1 & p99 & Skew. & Kurt. \\
\hline $\mathrm{x} 1$ & 9 & 8.987 & .428 & 8.276 & 9.465 & 8.276 & 9.465 & -.47 & 1.853 \\
\hline $\mathrm{x} 2$ & 9 & 6.523 & .26 & 6.097 & 6.905 & 6.097 & 6.905 & -.243 & 2.064 \\
\hline $\mathrm{x} 3$ & 9 & 9.099 & .101 & 8.87 & 9.19 & 8.87 & 9.19 & -1.419 & 3.984 \\
\hline $\mathrm{x} 4$ & 9 & 13.451 & .241 & 13.089 & 13.799 & 13.089 & 13.799 & .002 & 1.831 \\
\hline $\mathrm{x} 5$ & 9 & 10.832 & .225 & 10.499 & 11.161 & 10.499 & 11.161 & .036 & 1.834 \\
\hline
\end{tabular}

\section{Results and Discussion}

Table 3. Correlation analysis results.

\begin{tabular}{|l|l|l|l|l|l|}
\hline Variables & $x 1$ & $x 2$ & $x 3$ & $x 4$ & $x 5$ \\
\hline$(1) \times 1$ & $\mathbf{0 . 1 1 8 3 1 4}$ & & & & \\
\hline$(2) \times 2$ & $\mathbf{0 . 0 4 3 0 6 2}$ & $\mathbf{0 . 0 6 7 7 8 1}$ & & & \\
\hline (3) $x 3$ & $\mathbf{0 . 0 3 6 9 2 6}$ & $\mathbf{0 . 0 1 7 3 9 7}$ & $\mathbf{0 . 0 1 0 1 7 6}$ & & \\
\hline (4) $x 4$ & $\mathbf{0 . 1 0 0 6 5}$ & $\mathbf{0 . 0 1 4 8 0 7}$ & $\mathbf{0 . 0 2 0 0 1 3}$ & $\mathbf{0 . 0 5 8 0 7 9}$ & \\
\hline$(5) \times 5$ & $\mathbf{0 . 0 9 3 5 7 5}$ & $\mathbf{0 . 0 1 3 2 8 6}$ & $\mathbf{0 . 0 1 8 5 1 5}$ & $\mathbf{0 . 0 5 4 0 9 9}$ & $\mathbf{0 . 0 5 0 4 0 7}$ \\
\hline
\end{tabular}

From the correlation analysis results in Table 3, it can be seen that there is a significant positive correlation between the variable insurance claims X1 and the variables, indicating that the development of green insurance can have a positive impact on the growth of GDP and per capita GDP, and can promote economic growth and improve residents. Average income. At the same time, the development of the insurance industry has increased industrial pollution control funds and environmental protection investment funds, and improved industrial pollution control capabilities and environmental protection capabilities. The empirical results support the hypothesis.

Table 4. Matrix of correlations.

\begin{tabular}{|l|c|c|c|c|c|}
\hline Variables & (1) & (2) & (3) & (4) & (5) \\
\hline$(1) \times 1$ & 1.000 & & & & \\
\hline$(2) \times 2$ & 0.386 & 1.000 & & & \\
\hline$(3) \times 3$ & 0.855 & 0.662 & 1.000 & & \\
\hline$(4) \times 4$ & 0.976 & 0.236 & 0.823 & 1.000 & \\
\hline$(5) \times 5$ & 0.974 & 0.227 & 0.817 & 1.000 & 1.000 \\
\hline
\end{tabular}


The correlation covariance matrix in Table 4 shows the significance of the correlation between insurance industry compensation funds and other variables. It can be seen that the development of the insurance industry has a significant relationship with social and economic development, environmental pollution control and environmental protection, and the results support the previous hypothesis.

Table 5. Pairwise correlations.

\begin{tabular}{|l|l|l|l|l|l|}
\hline Variables & (1) & (2) & (3) & (4) & (5) \\
\hline$(1) \times 1$ & 1.000 & & & & \\
\hline & & & & & \\
\hline$(2) \times 2$ & 0.386 & 1.000 & & & \\
\hline & $(0.973)$ & & & & \\
\hline$(3) \times 3$ & 0.855 & 0.662 & 1.000 & & \\
\hline & $(0.032)$ & $(0.413)$ & & & \\
\hline$(4) \times 4$ & 0.976 & 0.236 & 0.823 & 1.000 & \\
\hline & $(0.000)$ & $(1.000)$ & $(0.062)$ & & \\
\hline$(5) \times 5$ & 0.974 & 0.227 & 0.817 & 1.000 & 1.000 \\
\hline & $(0.000)$ & $(1.000)$ & $(0.069)$ & $(0.000)$ & \\
\hline
\end{tabular}

Through the double correlation significance test in Table 5, it can be found that $\mathrm{x} 1, \mathrm{x} 2$, and $\mathrm{x} 3$ have passed the significance test, indicating that the development of green insurance has a greater contribution to the governance of industrial pollution and the improvement of environmental protection capabilities than to economic growth. The development of green insurance is conducive to the green transformation of Chinese industrial enterprises and plays an important role in the upgrading and transformation of Chinese industries.

In order to meet regulatory requirements and market demands, Chinese insurance companies have successively developed environmental pollution liability insurance, new energy insurance, forest and grassland insurance, wildlife accident insurance, chemical disposal insurance, green construction insurance, and other green insurances. Green insurance also includes the green use of insurance funds. Environmental pollution liability insurance is a typical green insurance.[9]

Accordingly, to integrity green financial system, governments, financial institutions, enterprises, and consumers need sparticipation and cooperation among each other.[10] China's green insurance mechanism is constructed under a government-guided and marketled model. Covers risk management, compensation for environmental accidents and compensation for environmental restoration. A green insurance operating mechanism with insurance companies as the core organization has been established. In the form of commercial insurance, the government, enterprises, and individual stakeholders are connected. After an environmental risk event occurs, green insurance can provide compensation for enterprises and individuals and diversify risks. Findings indicate that the mere presence of a market for insurance increases, overall, investment in profitable but risky inputs. [11]At the same time, it reduces the burden of the government on pollution control and environmental protection. In order to maintain sustainable development and profit, insurance companies will actively monitor the environmental risk behavior of the insured, which helps to detect and prevent the occurrence of environmental risk accidents in advance, there by reducing insurance compensation and increasing the benefits of green insurance.

Green insurance enables companies to obtain risk prevention and ex post compensation. Such an insurance mechanism can disperse the risks faced by enterprises in the process of transformation and innovation, especially the environmental risks of heavy industry enterprises. By providing guarantees for the quality and safety liability risks of innovative products and technologies in the green industry, providing compensation commitments and 
effective risk control services, enhancing the credit of green environmental protection behaviors, and providing funds for the development of environmentally friendly enterprises. At the same time, after the company has purchased environmental pollution liability insurance, once an environmental pollution accident occurs, the insurance company will provide economic compensation to the victim in accordance with the insurance contract, so that the environmental rights and interests of the victim are properly protected and avoid damage to the victim. A long-term and complicated situation. And high environmental risk companies have insured environmental pollution liability insurance, which is equivalent to the government and environmental protection departments finding a risk consultant and pollution accident handler, and the pressure on the government and environmental protection departments will also be relieved to a certain extent. This type of insurance operation is also conducive to safeguarding the public's environmental rights and interests and social equity.

Despite the rapid development of green insurance in China, there are still problems such as small premiums, low coverage, and weak corporate insurance and insurance institutions' weak willingness to conduct business. According to statistics, the percentage of all industrial companies insuring environmental liability insurance is less than $5 \%$, and the premiums for environmental liability insurance are only $1 \%$ of all premiums charged. Insurance companies face challenges such as information asymmetry and lack of environmental risk analysis capabilities. In terms of green insurance business, due to the large investment in product innovation, small customer base, high risk, low profit and other reasons, small and medium-sized insurance companies are not very active in developing green insurance business. Although these problems are improving due to the development of digital economy and insurance technology, they still obviously restrict the development of green insurance in China.

\section{Conclusion}

The development of China's green insurance has made up for the shortcomings of government and corporate functions, and has changed the previous development model of relying on the sacrifice of the environment to obtain economic growth. At the same time, it can provide financial support for environmental pollution control, improve environmental protection capabilities. China is poised to be a global leader in green finance policy implementation and regulators need to accelerate the formulation of green insurance products and enhance the capacity of financial institutions to offer green insurance. While minimizing the systemic risk fintech poses, policy makers should encourage fintechs to actively participate in environmental protection initiatives that promote green insurance. [13]

China committed to being carbon neutral by 2060, Either past successes or future ambitions cannot be achieved without policy support. Intensive efforts have been made by the Chinese government to cope with environmental degradation and pollution. In addition to comprehensive regulations and administrative enforcements, green finance policies have been explicitly introduced to support green development.[14]

China's 13th Five Year Plan proposed the creation of agreen financial system that encourages the private sector to play a more active role insustainable development.[15]On the basis of improving green insurance laws and regulations, the Chinese government has introduced systematic support policies, studied and formulated special development plans, implementation rules, and work plans, and improved preferential policies in terms of premium subsidies and green credit linkage. A coordination mechanism for relevant stakeholders in environmental protection, land, finance, agriculture, and insurance 
supervision has been formed, which has promoted the development of the green insurance industry from the national perspective.[16]

Establish a unified green insurance database to collect and manage national environmental pollution, environmental damage, energy conservation and emission reduction, pollution damage compensation expenditures and other data to form a shared database to provide data support for insurance product research and development, rate determination, underwriting, claims, services, etc. , Reshaping the green insurance industry chain and value chain.[17]

Realize the innovation of green insurance products through the development of financial technology, increase product coverage, and expand the scope of green insurance protection. With the help of financial technology and digital technology, insurance companies have designed scenario-based green insurance, launched green insurance with multiple risk protection functions, and developed the needs of the insured and the green insurance market.

The China Banking and Insurance Regulatory Commission has formulated the project standards for green insurance, which is conducive to the development of various green insurances such as catastrophe insurance, research and development liability insurance, green enterprise loan guarantee insurance, green construction insurance, and green enterprise important equipment insurance. [18]It encourages insurance funds to explore new paths for green investment, enhances green insurance's participation in green project investment and construction, and better meets the financial needs of green project investment and construction.[19]

Green insurance helps local governments, enterprises and households face losses from natural disasters caused by climate change, smoothes financial fluctuations, and enhances risk resilience. Green insurance provides insurance applicants with compensation commitments and effective risk control services through risk compensation integrated services, technology and other resource elements, which is conducive to the sustainable development of environmental protection companies. These measures can be used as a reference for developing countries to develop green finance and achieve sustainable development.

\section{References}

1. H. Niczyporuk, J. Urpelainen, J. Cleaner Pro. 281, 1 (2021)

2. Y.Y. Zheng, Economic Daily, 8, 5(2021), http://www.ce.cn.

3. Y.Q. Chen. B. Zhi, J. Miao, Construction Sci. Tech., 379, 51(2019)

4. J.Y. Chen, Southern Finance, 9, 14 (2016), http://www.nfjr.gd.cn

5. S.Q. Wang, J. Pang. B.Tianjin U. 3, 30(2019)

6. M. Zheng. B. Liaoning U. 1, 66 (2021)

7. L.H. Chen, J. Puyang Voc. Tech. Col. 2, 13 (2020)

8. W.G. Chan, P.Y. Nie, D.H. Peng, Z.H. Li. J. Cleaner Pro. 148, 112 (2017)

9. J.J. Wang, X.P. Jia, Resources, Con.\& Rec. 170, 1 (2021)

10. H.Cui, R.Wang, H.Wang, J. Cleaner Pro. 269, 14 (2020)

11. C. Falco, V. Rotondi, D. Kong, V. Spelta, Ecological Eco., 188, 1 (2021)

12. S. An, B. Li, D. Song, X. European. J. Ope.Res., 1, 126 (2020)

13. T. Muganyi, L.N. Yan, H.P. Sun. Environmental Sci. Eco., 7, 5 (2021), http://creativecommons.org

14. C.H. Yu, X.Q. Wu, D.Y. Zhang, S. Chen, J.S. Zhao. Energy Pol., 153, 1(2021)

15. J.Wang, X. Chen, X. Li, J. Yu, R. Zhong. P-B Finance J., 60, 1(2020)

16. M.S. Zhang, Y. Lian, H. Zhao, X.B.Chun. Energy Str. Rev., 30, 1(2020)

17. X.H. Xie, B. Tomsk S. U. Eco., 54, 235 (2021) 
18. Y.Shen, Z. W. Su, M. Y. Malik, M. Umar, Z. Khan, M. Khan. Total Env., 755, 1(2021)

19. H. Xu, Q. Mei, F. Shahzad, S.Liu, X. Long, J. Zhang, Sustainability, 12, 21(2020) 